Supporting Information

\title{
Supramolecular Control of Unwinding and Rewinding of a Double Helix of Oligoresorcinol Using Cyclodextrin/Adamantane System
}

\author{
Hidetoshi Goto, ${ }^{\dagger}$ Yoshio Furusho, ${ }^{*, \dagger}$ and Eiji Yashima ${ }^{*, \dagger, *}$
}

Yashima Super-structured Helix Project, Exploratory Research for Advanced Technology (ERATO), Japan Science and Technology Agency (JST), 101 Creation Core Nagoya, 2266-

22 Shimoshidami, Moriyama-ku, Nagoya 463-0003, Japan, and Institute for Advanced

Research, Nagoya University, Nagoya 464-8603, Japan

E-mail: furusho@yp-jst.jp; yashima@apchem.nagoya-u.ac.jp 
Table of Contents

$\begin{array}{ll}\text { 1. Instruments } & \text { S3 }\end{array}$

$\begin{array}{ll}\text { 2. Materials } & \mathrm{S} 3\end{array}$

3. Investigation of [3]Pseudorotaxane Formation

3-1. Complexation of 9merH with $\alpha$-, $\beta$-, and $\boldsymbol{\gamma}$-CDs $\quad$ S4

3-2. Titration Experiments $\quad$ S5

3-3. gCOSY and NOESY Analyses $\quad$ S9

3-4. Molecular Modeling and Calculations $\quad$ S14

4. Supramolecular Control of the Unwinding and Rewinding of the double helix of 9merH with CDs and an Adamantane Derivative $\quad$ S16

$\begin{array}{lr}\text { 5. References } & \text { S19 }\end{array}$ 


\section{Instruments}

The solution $\mathrm{pH}$ was measured with a DKK-TOA GST-5428S pH meter (Tokyo, Japan). The NMR spectra were obtained using a Varian UNITY INOVA 500AS spectrometer operating at $500 \mathrm{MHz}$ for ${ }^{1} \mathrm{H}$. Chemical shifts are reported in parts per million $(\delta)$ using acetone $(2.22 \mathrm{ppm})$ dissolved in $\mathrm{D}_{2} \mathrm{O}$ as the external standard. The absorption and circular dichroism spectra were measured in a $0.1-, 0.2$, or $1.0-\mathrm{mm}$ quartz cell on a Jasco V-570 spectrophotometer and a Jasco J-820 spectropolarimeter, respectively.

\section{Materials}

Oligoresorcinol nonamer, 9merH was synthesized according to the previous literature. ${ }^{1}$ $\alpha-\beta$-, and $\gamma$-Cyclodextrins (CDs) and 1-aminoadamantane hydrochloride (Ad) were purchased from Wako Pure Chemical Industries (Osaka, Japan). The distilled water and $\mathrm{D}_{2} \mathrm{O}(99.9$ atom \%D) purchased from Wako and Cambridge Isotope Laboratories (Andover, MA, USA), respectively, were degassed with Ar and used throughout all the experiments. 


\section{Investigation of [3]Pseudorotaxane Formation}

\section{3-1. Complexation of 9merH with $\alpha$-, $\beta$-, and $\gamma$-CDs}

The ${ }^{1} \mathrm{H}$ NMR spectral changes of 9 merH in the presence of $\alpha$-, $\beta$ - and $\gamma$-CDs in $\mathrm{D}_{2} \mathrm{O}$ indicate that 9merH forms the [3]pseudorotaxanes selectively with $\beta$ - and $\gamma$-CDs.
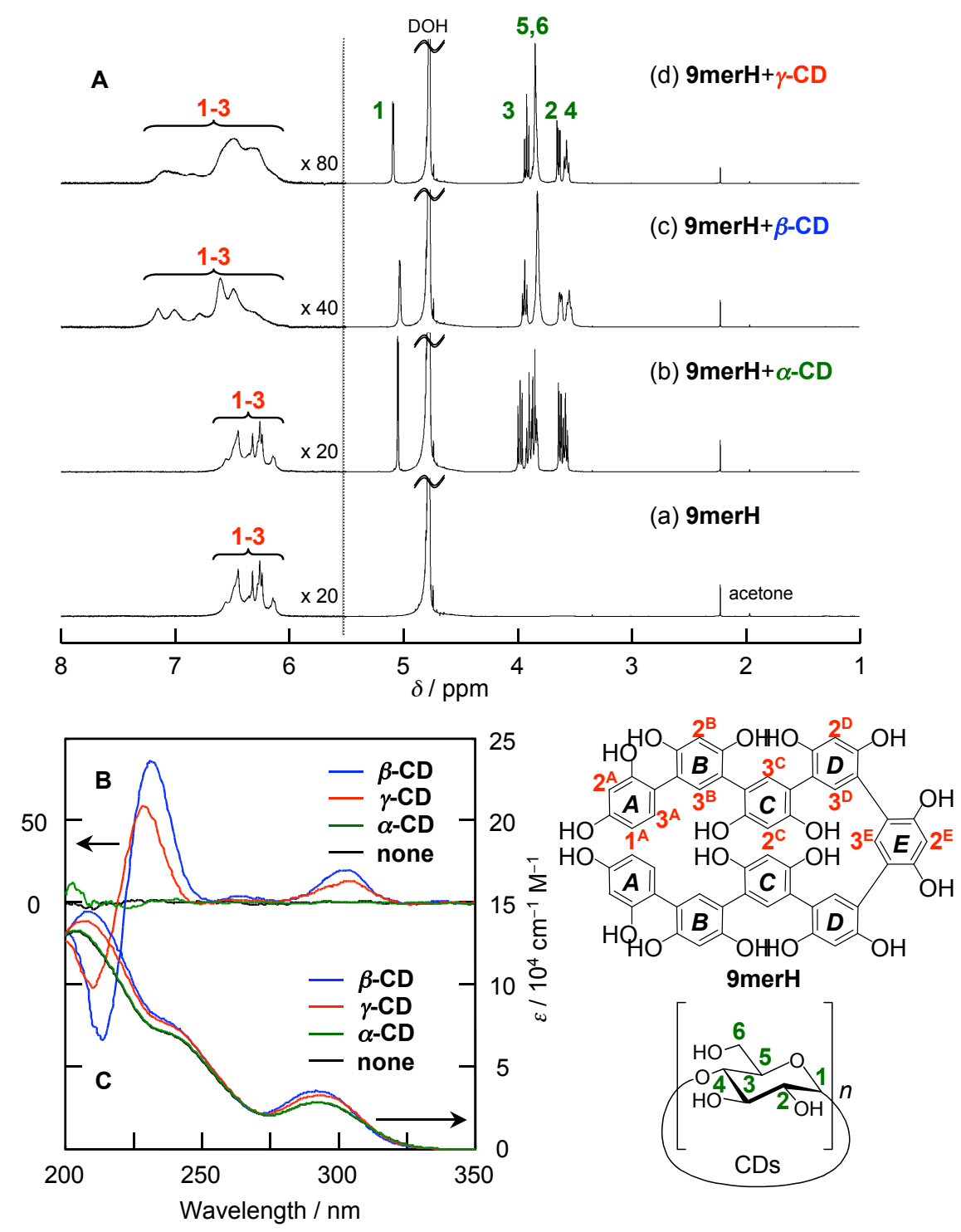

Figure S1. ${ }^{1} \mathrm{H}$ NMR (A), circular dichroism (B) and absorption spectra (C) of 9merH in the presence of CDs (none, $\alpha-\mathrm{CD}, \beta-\mathrm{CD}$, and $\gamma-\mathrm{CD}$ ) in $\mathrm{D}_{2} \mathrm{O}(\mathrm{pD}=5.5-5.7)$ at $25{ }^{\circ} \mathrm{C}$. $[9 \mathrm{merH}]=0.625 \mathrm{mM},[\mathrm{CD}]=5 \mathrm{mM},[\mathrm{CD}] /[9 \mathrm{merH}]=8$. 


\section{3-2. Titration Experiments}

The titration experiments of 9 merH with $\beta$ - and $\gamma$-CDs indicate that the double helix of 9merH dissociates into the corresponding single strands, resulting in the formation of [3]pseudorotaxanes in which the 9merH strand encapsulated in the chiral CD cavities adopts a helical conformation with an excess of the preferred helix-sense. The Job's plot suggests the 1:2 [3]pseudorotaxane formation.

\section{9merH- $\beta$-CD}
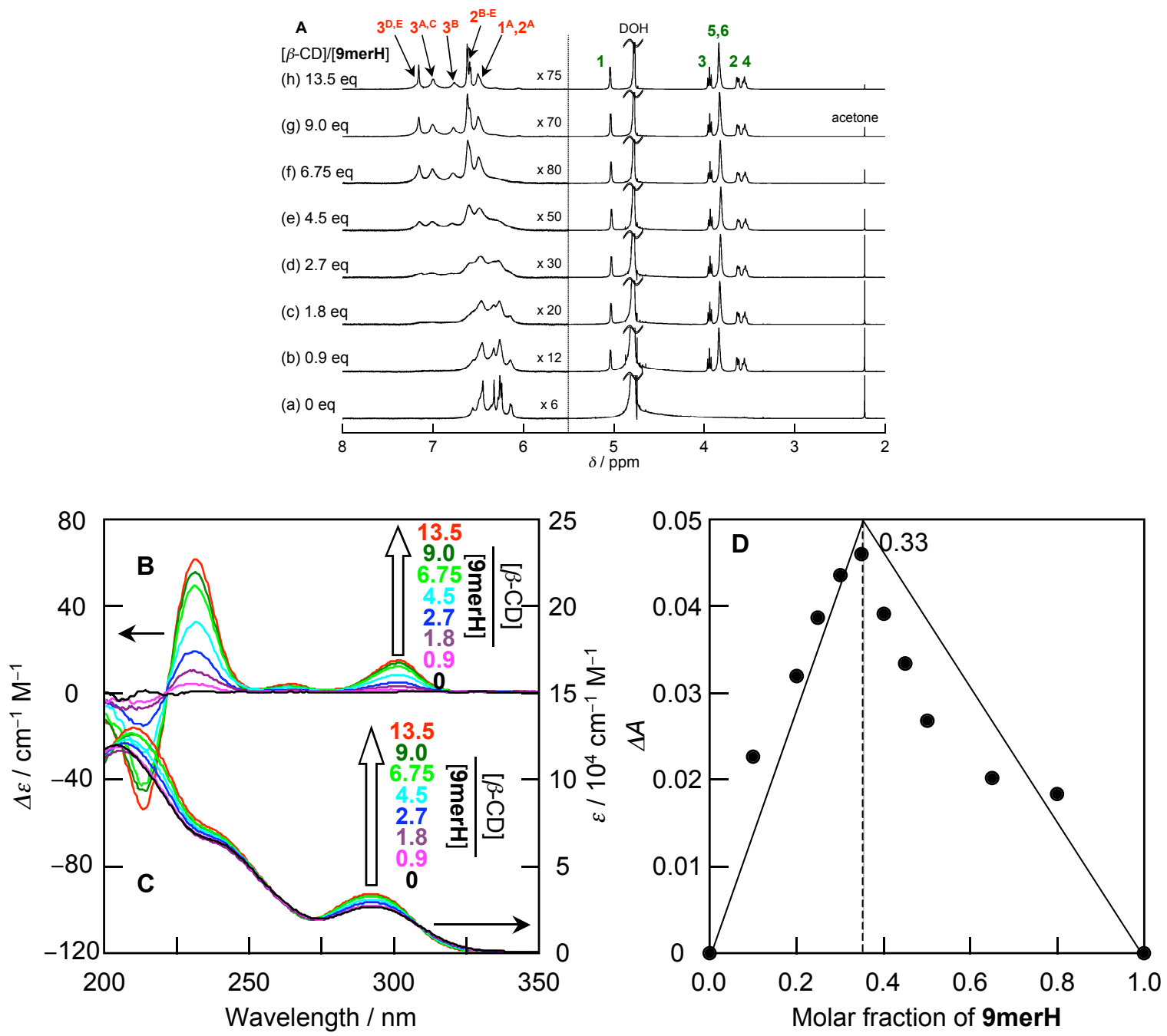

Figure S2. ${ }^{1} \mathrm{H}$ NMR (A), circular dichroism (B) and absorption spectra (C) of 9merH with $\beta-\mathrm{CD}$ in $\mathrm{D}_{2} \mathrm{O}(\mathrm{pD}=5.3-6.8)$ at $25{ }^{\circ} \mathrm{C}$. $[9 \mathrm{merH}]=1 \mathrm{mM},[\beta-\mathrm{CD}] /[9 \mathrm{merH}]=0-13.5$. (D) Job's plot of 9merH with $\beta$-CD in $\mathrm{H}_{2} \mathrm{O}$; molar fraction of 9merH vs. $\Delta A_{293}\left(=A_{\text {measured }}-\right.$ $\left.A_{\text {expected }}\right) ;[\mathbf{9 m e r H}]+[\beta-\mathrm{CD}]=4 \mathrm{mM}$ (constant). 


\section{9merH- $\gamma$-CD}
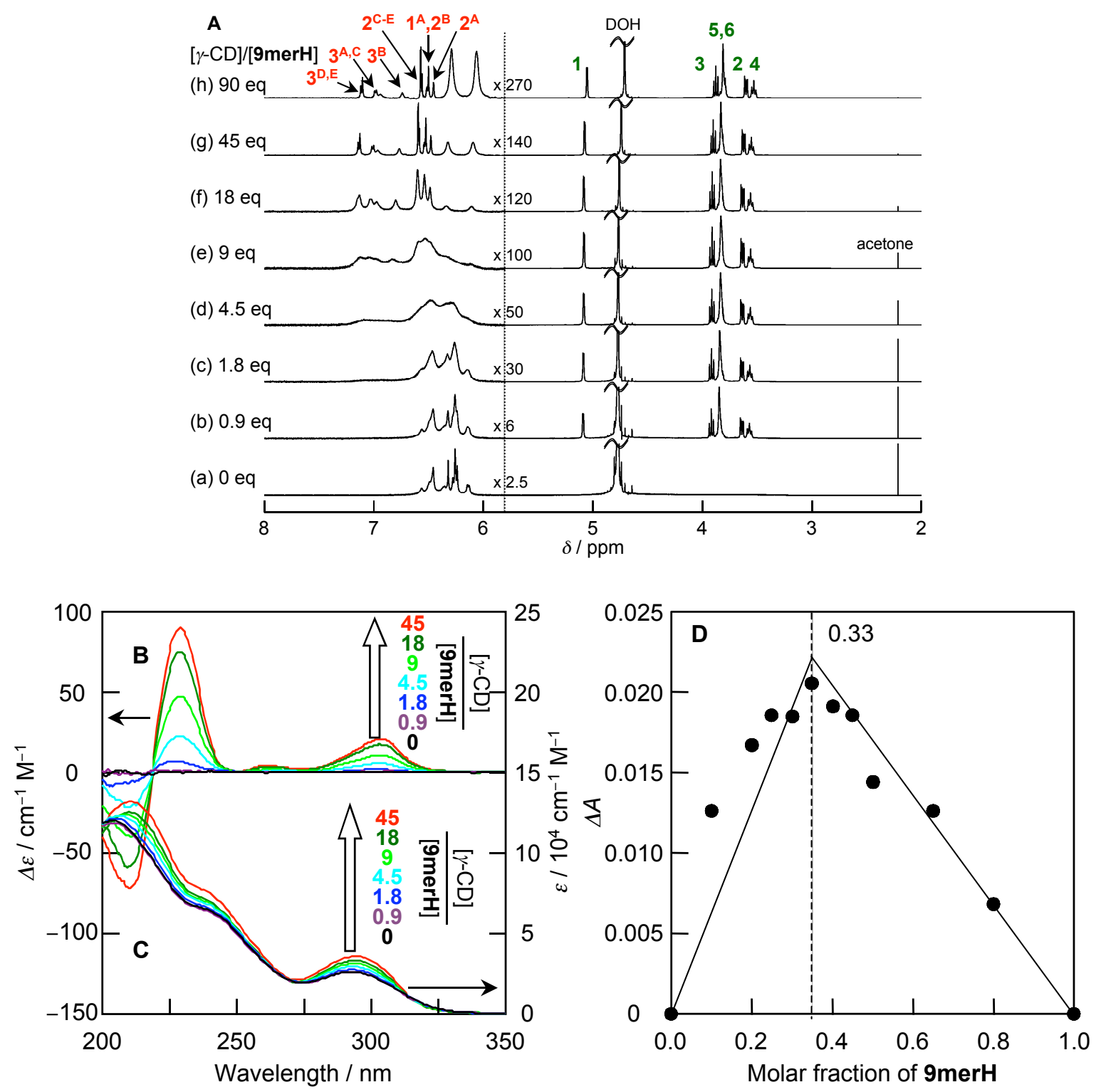

Figure S3. ${ }^{1} \mathrm{H}$ NMR (A), circular dichroism (B) and absorption spectra (C) of 9merH with $\gamma$-CD in $\mathrm{D}_{2} \mathrm{O}(\mathrm{pD}=5.3-6.8)$ at $25{ }^{\circ} \mathrm{C}$. $[9 \mathbf{m e r H}]=1 \mathrm{mM},[\gamma-\mathrm{CD}] /[9 \mathbf{m e r H}]=0-90$. (D) Job's plot of 9merH with $\gamma-\mathrm{CD}$ in $\mathrm{H}_{2} \mathrm{O}$; molar fraction of 9merH vs. $\Delta A_{293}\left(=A_{\text {measured }}-\right.$ $\left.A_{\text {expected }}\right) ;[9 \mathbf{m e r H}]+[\gamma-\mathrm{CD}]=4 \mathrm{mM}$ (constant). 
The association constants for the [3]pseudorotaxane formation with $\beta$ - and $\gamma$-CDs were roughly evaluated by assuming the following, simplified equilibrium 1 that neglects the single-stranded species of $\mathbf{9 m e r H}$. The association constants were calculated by a singlepoint determination at each point of the titration.

$$
\begin{aligned}
& (\text { 9merH })_{2}+4 \times \mathrm{CD} \stackrel{K_{1}}{\rightleftarrows} \quad 2 \times \text { 9merH } \mathrm{CD}_{2} \\
& K_{1}=\frac{\left[\text { 9merH } \cdot \mathrm{CD}_{2}\right]^{2}}{\left[(\text { 9merH })_{2}\right][\mathrm{CD}]^{4}}
\end{aligned}
$$

A: $\beta$-CD

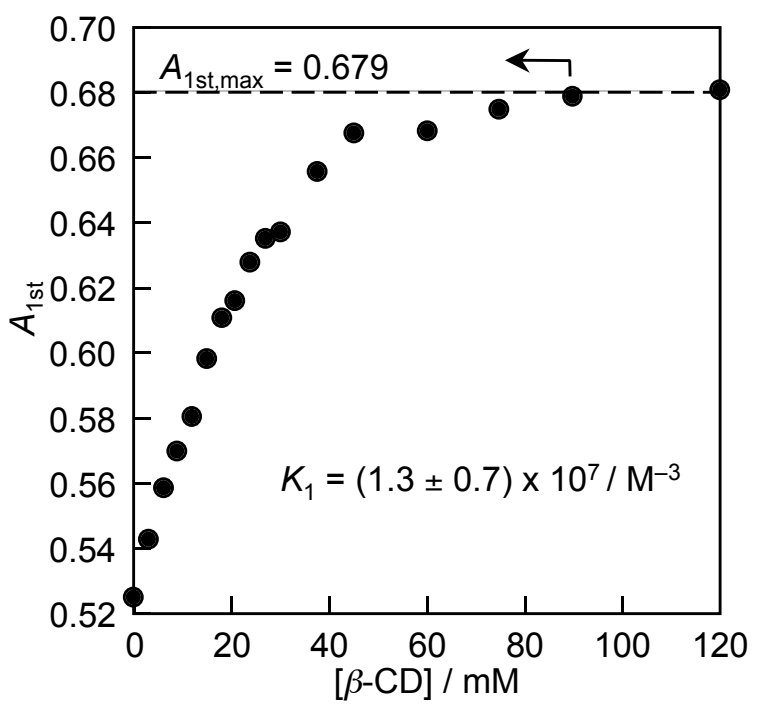

B: $\gamma-C D$

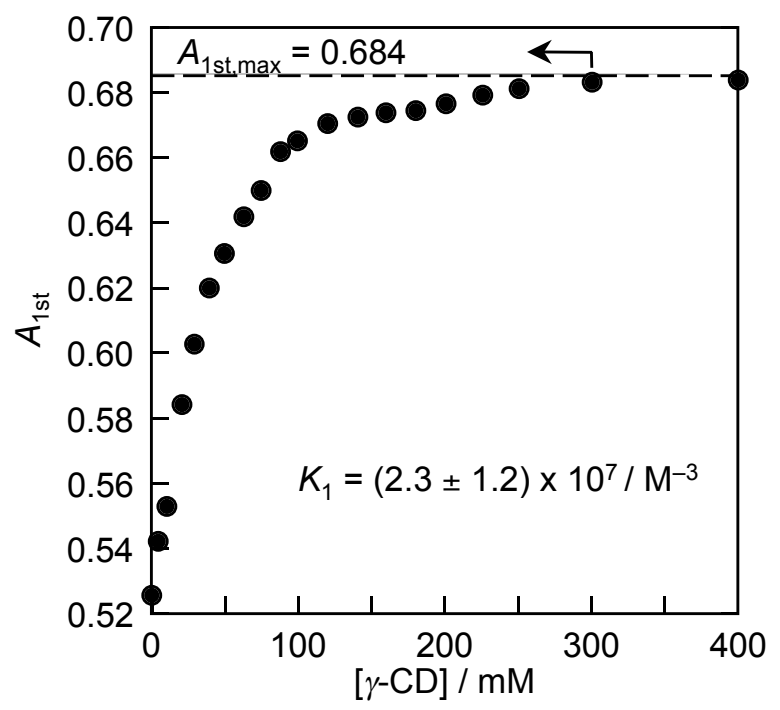

Figure S4. Plots of absorbances $\left(A_{1 \mathrm{st}}\right)$ at $c a .293 \mathrm{~nm}$ of 9 merH with $\beta$-CD (A) and $\gamma$-CD (B) versus the concentration of $\mathrm{CDs}$ in $\mathrm{H}_{2} \mathrm{O}(\mathrm{pH}=4.8-5.2)$ at $25^{\circ} \mathrm{C}$. 
The binding constant of Ad with $\gamma$-CD was determined to be $4.0 \pm 0.5 \mathrm{M}^{-1}$ by ${ }^{1} \mathrm{H}$ NMR titration, as shown below.

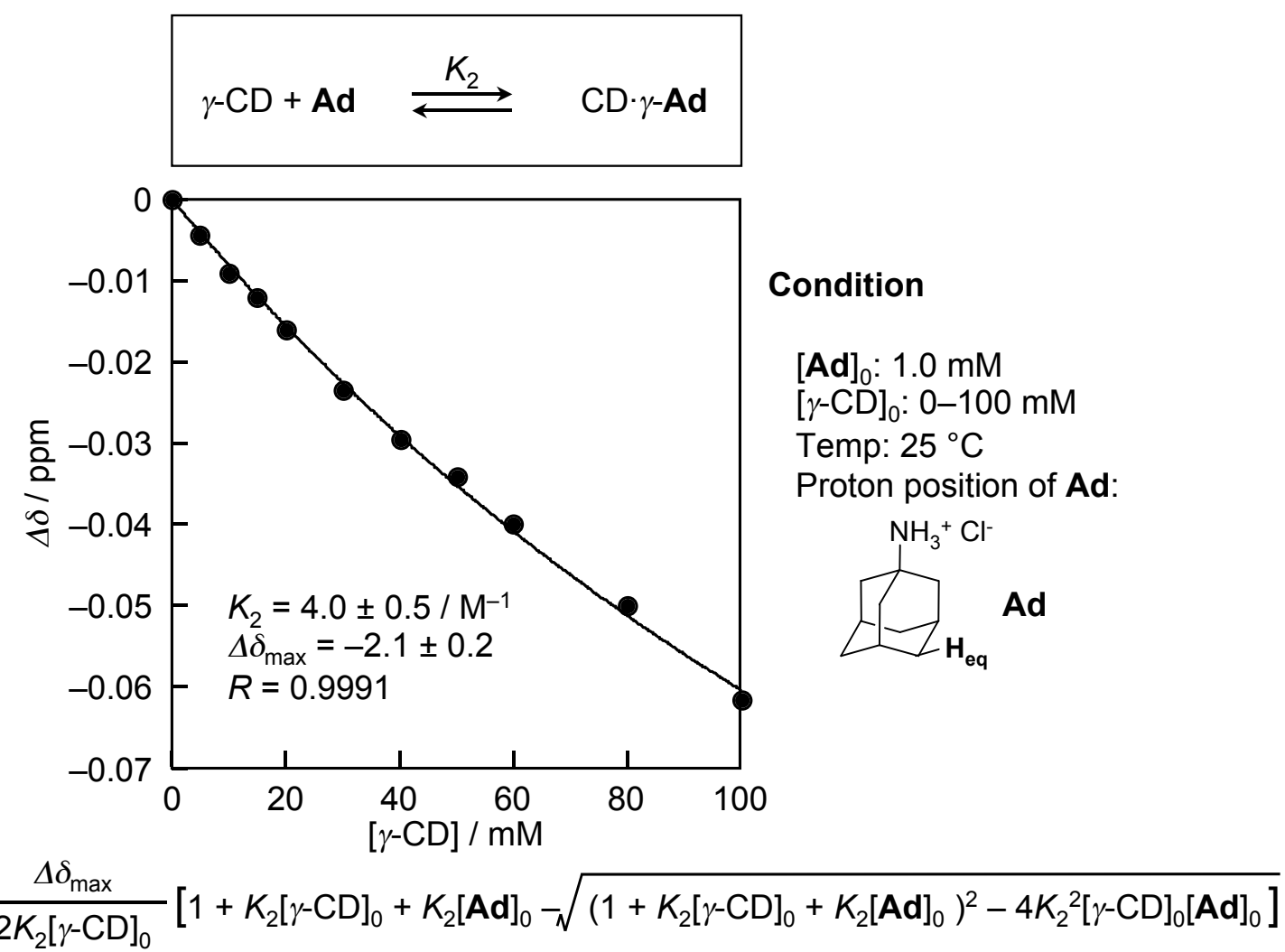

Figure S5. Plot of $\Delta \delta$ of the equatorial proton of 1-aminoadamantane hydrochloride (Ad) versus the concentrations of $\gamma-\mathrm{CD}$ in $\mathrm{D}_{2} \mathrm{O}(\mathrm{pD}=5.6-6.0)$ at $25^{\circ} \mathrm{C}$. The solid line in the plot represents the curve fittings according to the above equation. 


\section{3-3. gCOSY and NOESY Analysis}

The NOESY spectra of the complexes between 9merH and $\beta$ - and $\gamma$-CDs indicate that the 9merH strand penetrates from the narrower rim of $\beta$ - and $\gamma$-CDs to form the [3]pseudorotaxane in a head-to-head fashion (Fig. 1E).

\section{gCOSY Spectra of 9merH- $\beta$-CD}

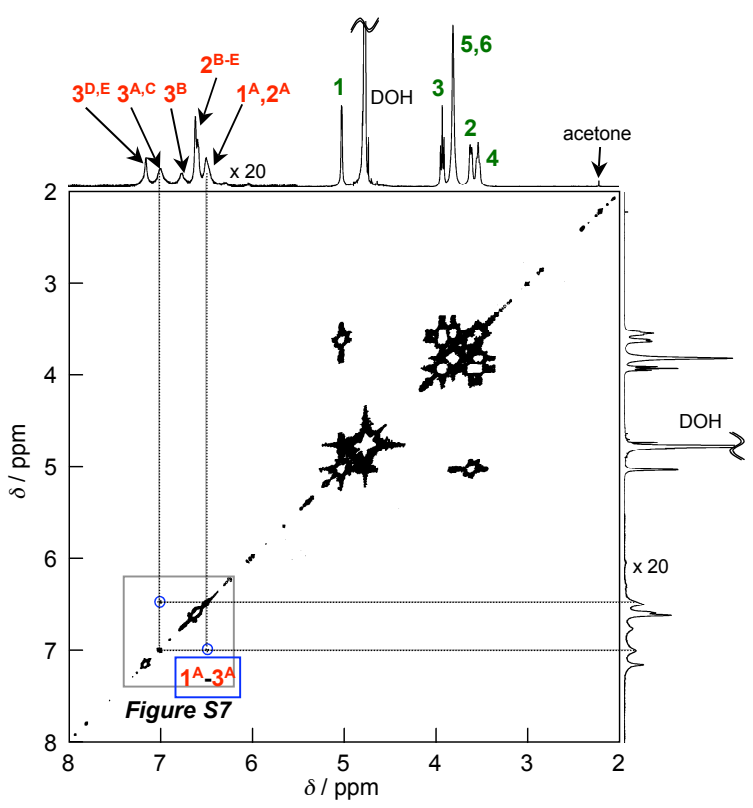

Figure S6. gCOSY spectrum $(\delta: 2-8 \mathrm{ppm})$ of 9 merH with $\beta$-CD in $\mathrm{D}_{2} \mathrm{O}$ at $25^{\circ} \mathrm{C}$. [9merH] $=2 \mathrm{mM},[\beta-\mathrm{CD}] /[\mathbf{9 m e r H}]=9$.

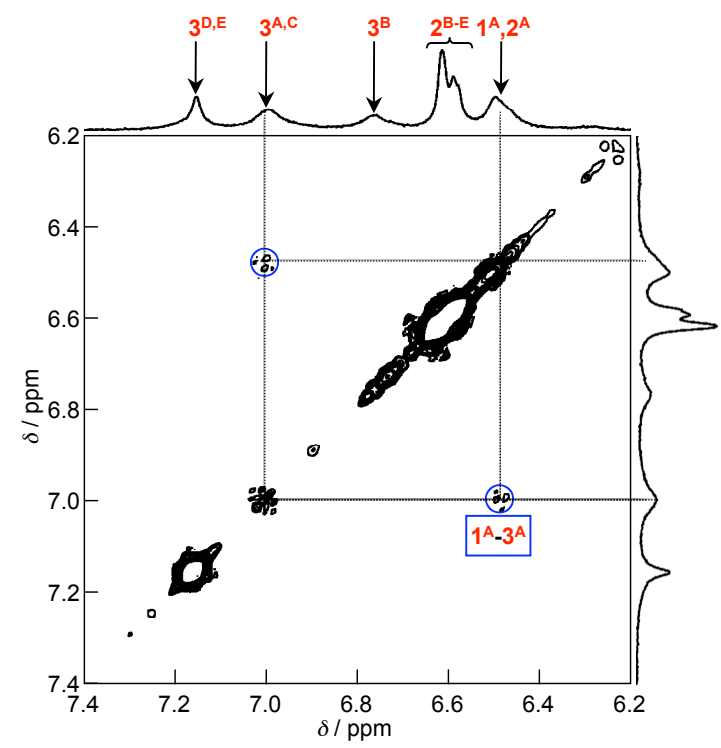

Figure S7. Partial gCOSY spectrum $(\delta: 6.2-7.4 \mathrm{ppm})$ of 9 merH with $\beta$-CD in $\mathrm{D}_{2} \mathrm{O}$ at 25 ${ }^{\circ} \mathrm{C} .[9 \mathbf{m e r H}]=2 \mathrm{mM},[\beta-\mathrm{CD}] /[\mathbf{9 m e r H}]=9$. 

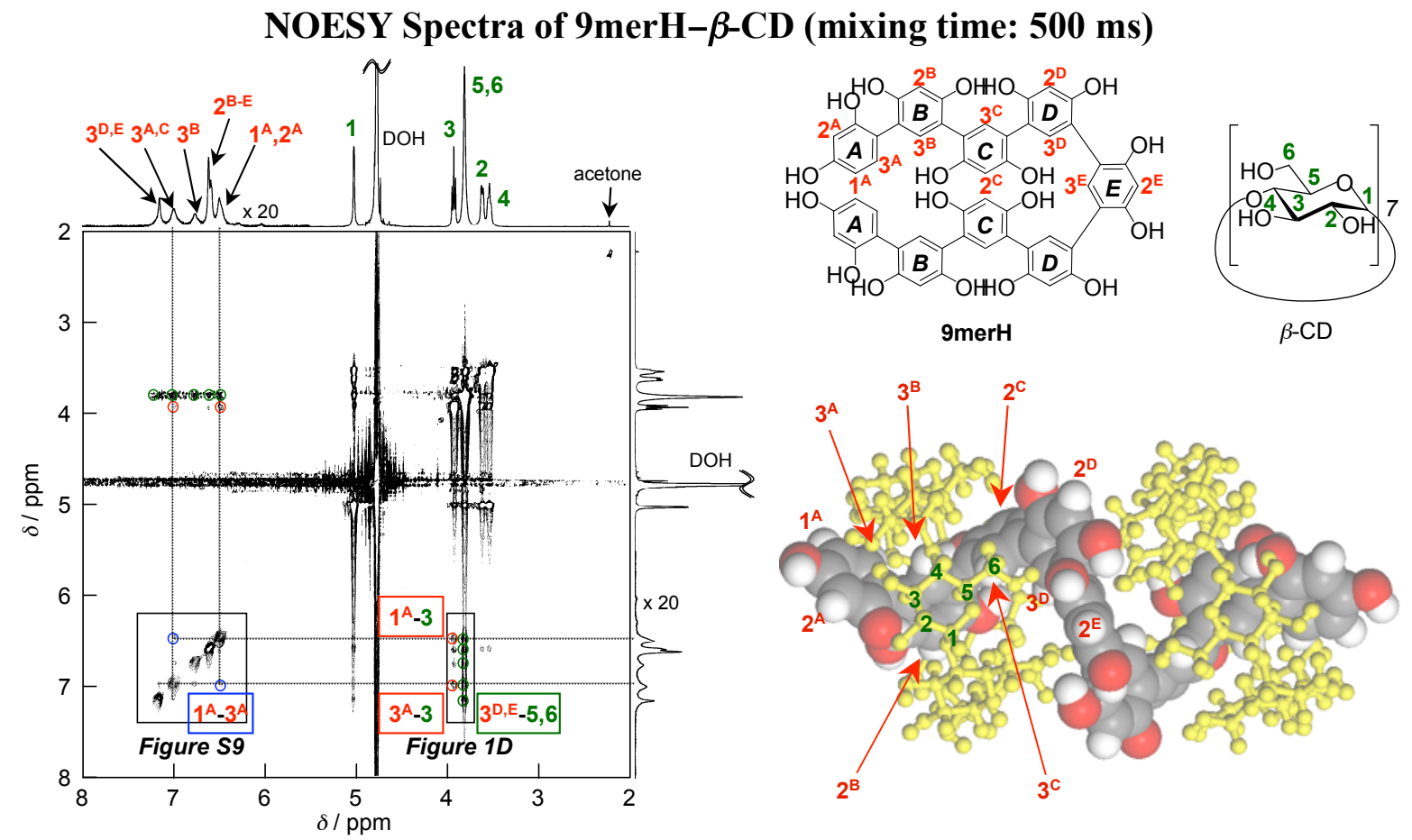

Figure S8. NOESY spectrum ( $\delta$ : $2-8 \mathrm{ppm}$ ) (mixing time: $500 \mathrm{~ms}$ ) of 9merH with $\beta$-CD in $\mathrm{D}_{2} \mathrm{O}$ at $25{ }^{\circ} \mathrm{C}$. $[\mathbf{9 m e r H}]=2 \mathrm{mM},[\beta-\mathrm{CD}] /[\mathbf{9 m e r H}]=9$.

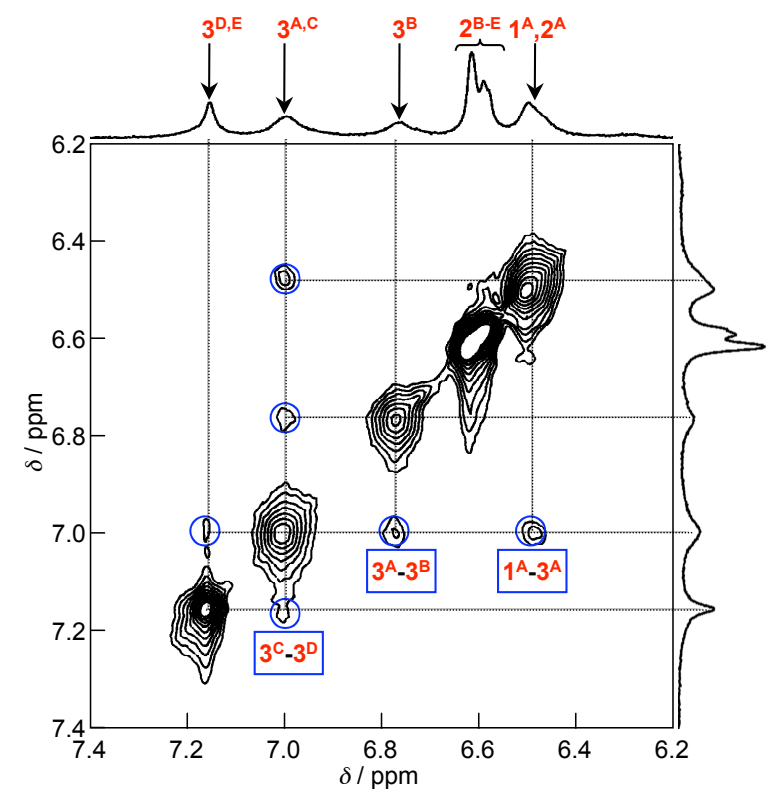

Figure S9. Partial NOESY spectrum ( $\delta$ : $6.2-7.4 \mathrm{ppm}$ ) (mixing time: $500 \mathrm{~ms}$ ) of 9merH with $\beta-\mathrm{CD}$ in $\mathrm{D}_{2} \mathrm{O}$ at $25^{\circ} \mathrm{C}$. $[\mathbf{9 m e r H}]=2 \mathrm{mM},[\beta-\mathrm{CD}] /[\mathbf{9 m e r H}]=9$. 


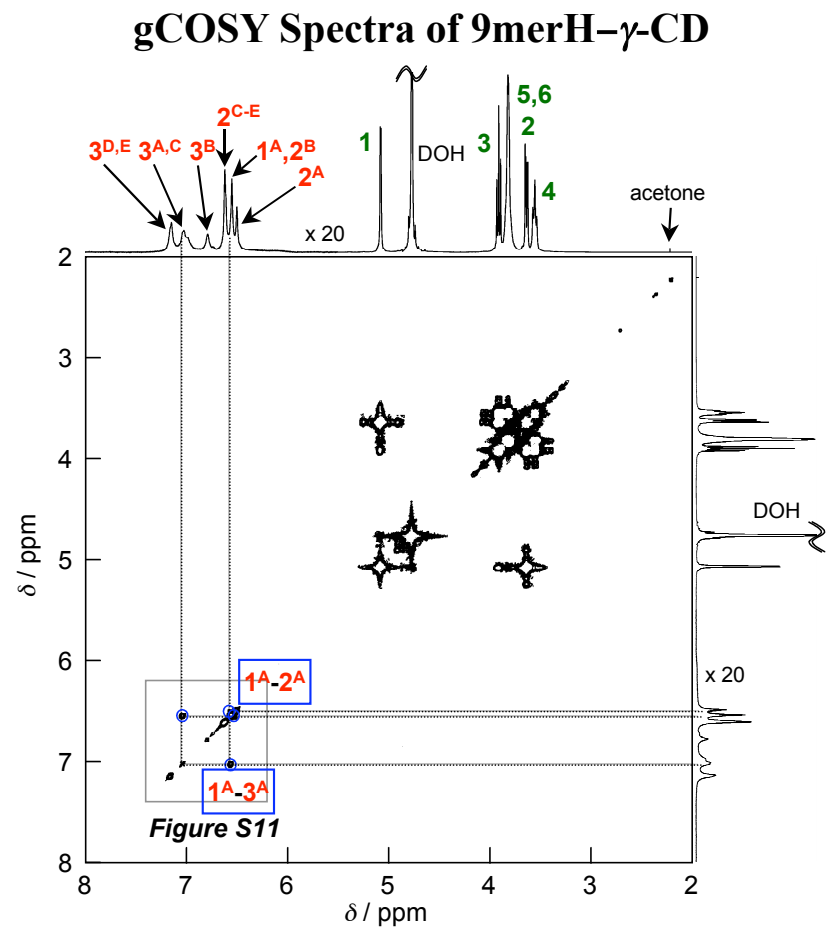

Figure S10. gCOSY spectrum $(\delta: 2-8 \mathrm{ppm})$ of 9merH with $\gamma$-CD in $\mathrm{D}_{2} \mathrm{O}$ at $25{ }^{\circ} \mathrm{C}$. $[\mathbf{9 m e r H}]=2 \mathrm{mM},[\gamma-\mathrm{CD}] /[\mathbf{9 m e r H}]=9$.

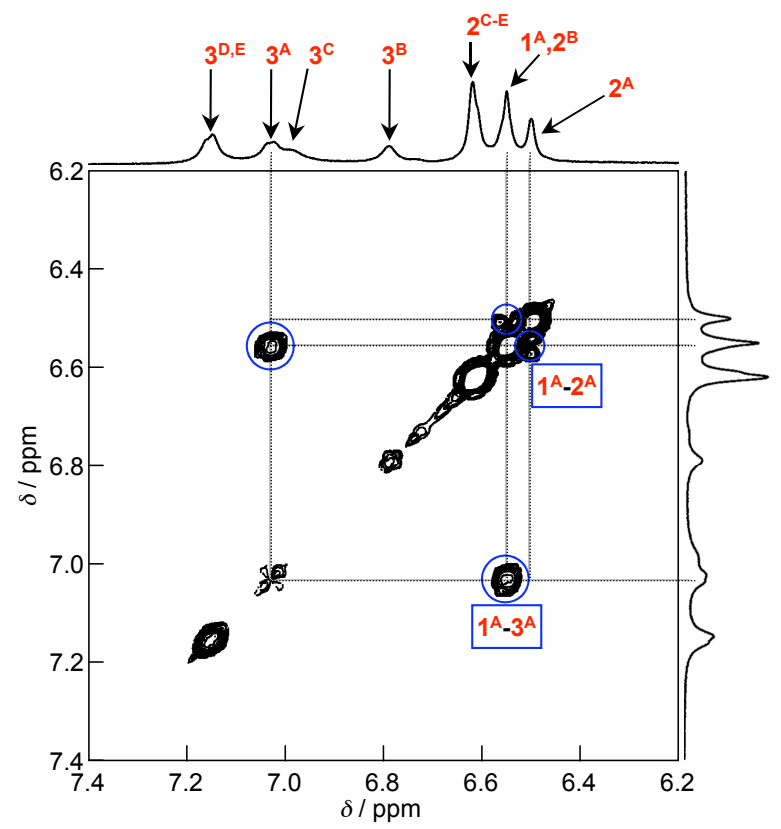

Figure S11. Partial gCOSY spectrum ( $\delta: 6.2-7.4 \mathrm{ppm})$ of 9 merH with $\gamma-\mathrm{CD}$ in $\mathrm{D}_{2} \mathrm{O}$ at 25 ${ }^{\circ} \mathrm{C} .[9 \mathrm{merH}]=2 \mathrm{mM},[\gamma-\mathrm{CD}] /[\mathbf{9 m e r H}]=9$. 
NOESY Spectra of 9merH- $\gamma$-CD (mixing time: $500 \mathrm{~ms}$ )

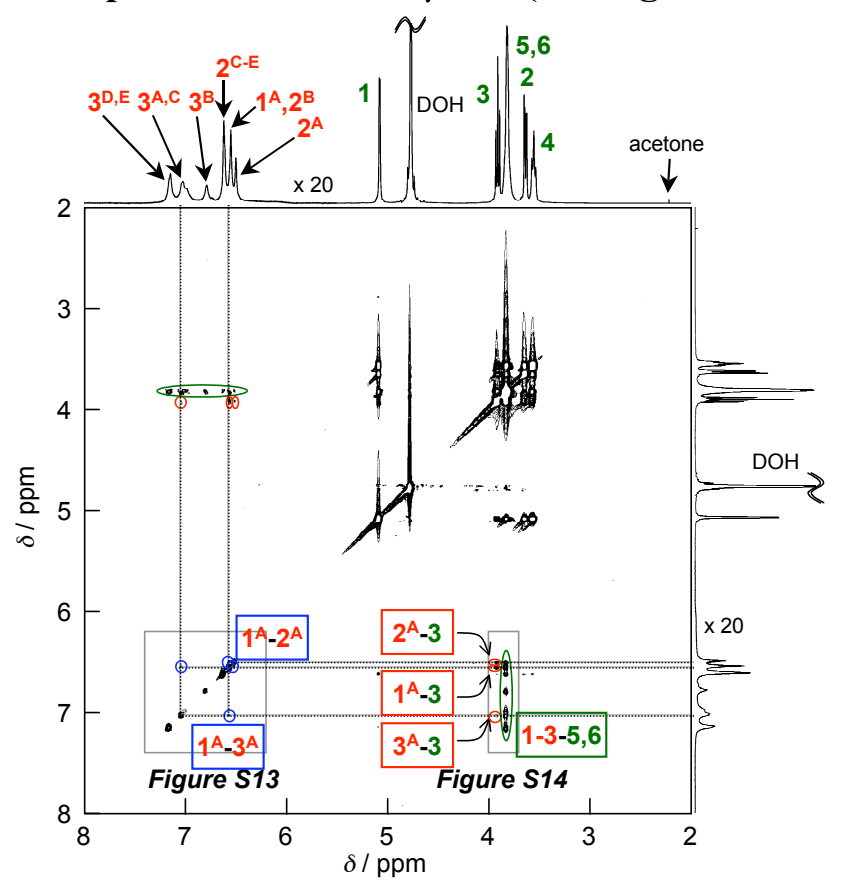

Figure S12. NOESY spectrum ( $\delta: 2-8 \mathrm{ppm}$ ) (mixing time: $500 \mathrm{~ms}$ ) of 9merH with $\gamma$-CD in $\mathrm{D}_{2} \mathrm{O}$ at $25{ }^{\circ} \mathrm{C}$. $[\mathbf{9 m e r H}]=2 \mathrm{mM},[\gamma-\mathrm{CD}] /[\mathbf{9 m e r H}]=9$.

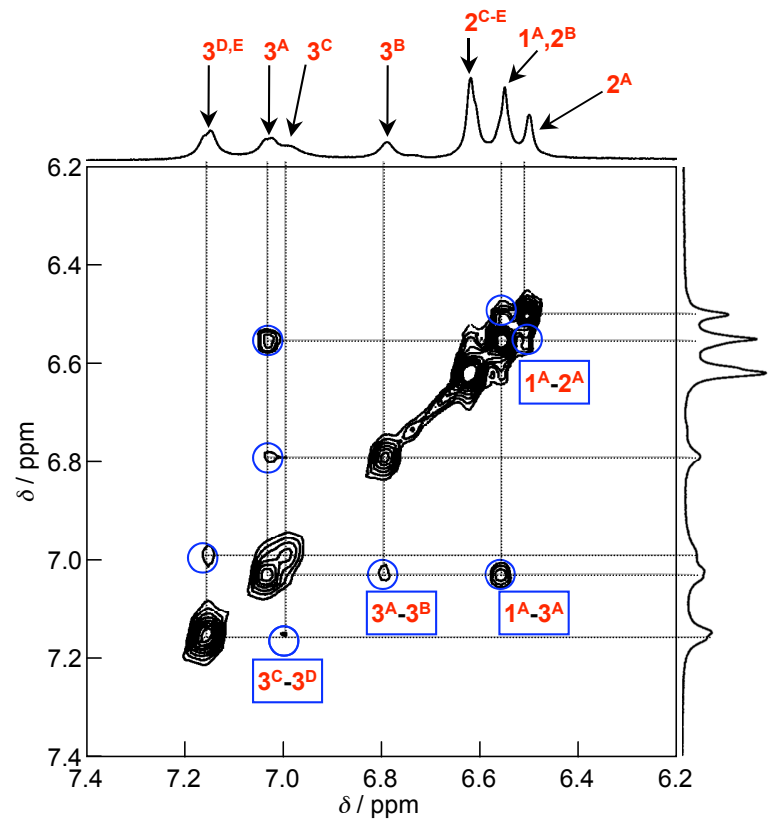

Figure S13. Partial NOESY spectrum ( $\delta: 6.2-7.4 \mathrm{ppm})$ (mixing time: $500 \mathrm{~ms}$ ) of 9merH with $\gamma-\mathrm{CD}$ in $\mathrm{D}_{2} \mathrm{O}$ at $25^{\circ} \mathrm{C}$. $[\mathbf{9 m e r H}]=2 \mathrm{mM},[\gamma-\mathrm{CD}] /[\mathbf{9 m e r H}]=9$. 

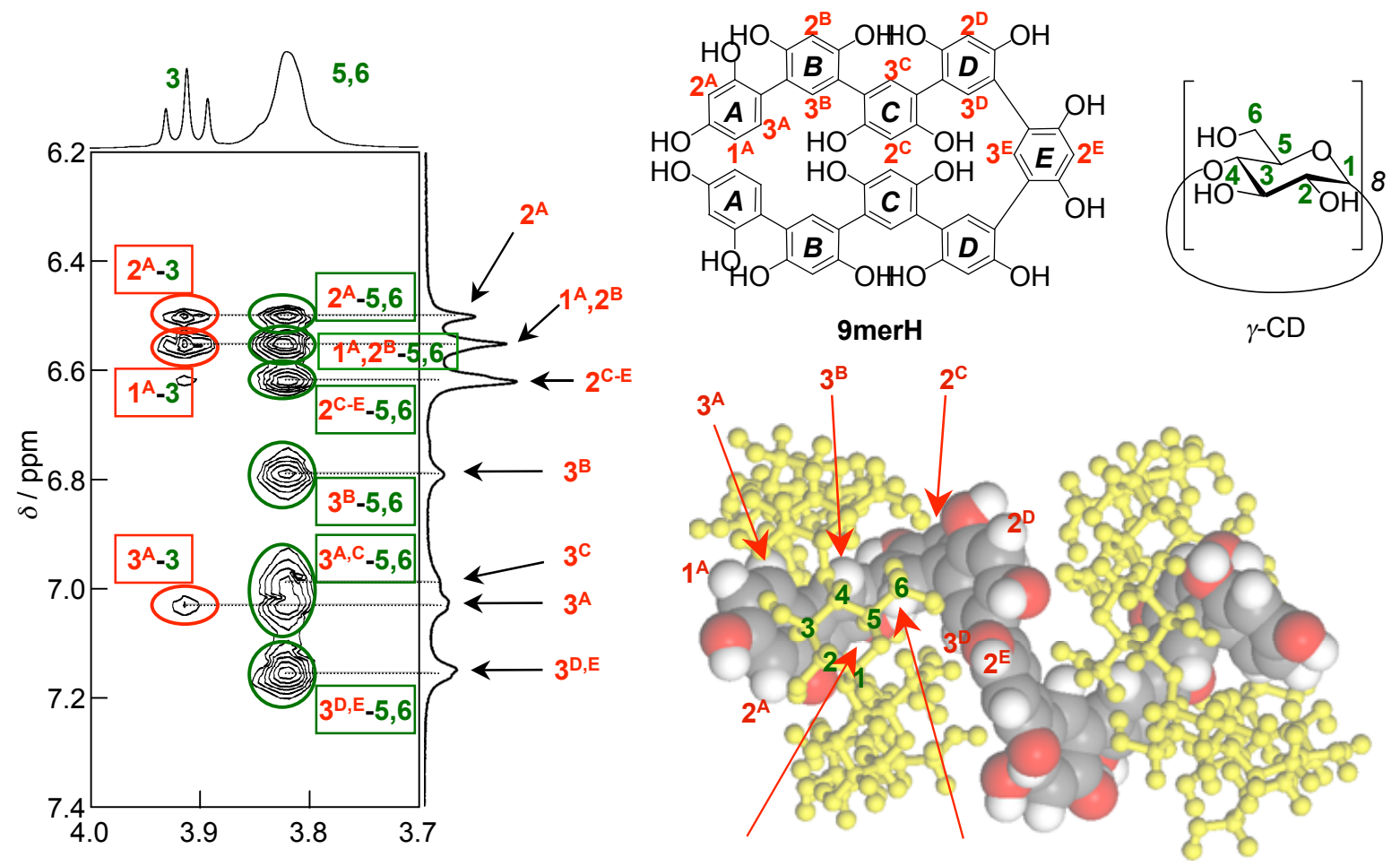

Figure S14. Partial NOESY spectrum (mixing time: $500 \mathrm{~ms}$ ) of 9 merH with $\gamma$-CD in $\mathrm{D}_{2} \mathrm{O}$ at $25{ }^{\circ} \mathrm{C} .[9 \mathbf{m e r H}]=2 \mathrm{mM},[\gamma-\mathrm{CD}] /[\mathbf{9 m e r H}]=9$. 


\section{3-4. Molecular Modeling and Calculations}

Molecular modeling and molecular mechanics calculations were performed using the Compass Force Field as implemented in the Materials Studio software (version 3.0; Accerlys Inc.). The models of the [3]pseudorotaxanes 9merH $(\beta-C D)_{2}$ and 9 merH $\cdot(\gamma-C D)_{2}$ were constructed using Materials Visualizer in the Materials Studio. The parameter, "relative electric" was set to 4 that is the recommended value for calculations in water. The calculated model of the double helix of $\mathbf{9 m e r H}$ was used according to the previous literature. ${ }^{1}$ Charges on the atoms of the oligomers were calculated using the charge equilibration $(\mathrm{QEq})$ in the Materials Studio; the total charge of the molecule was set to zero. Two $\beta$ - or $\gamma$-CD molecules were threaded from the narrower rim in a head-to-head fashion onto the single strand of $\mathbf{9 m e r H}$, of which the structure was taken from one of the strands of the energy-minimized structure of the 9merH double helix. The energy minimization was conducted using the Smart Minimizer of the Discover module until the root-meansquare (rms) value became less than $0.1 \mathrm{kcal} \mathrm{mol}^{-1} \AA^{-1}$. 


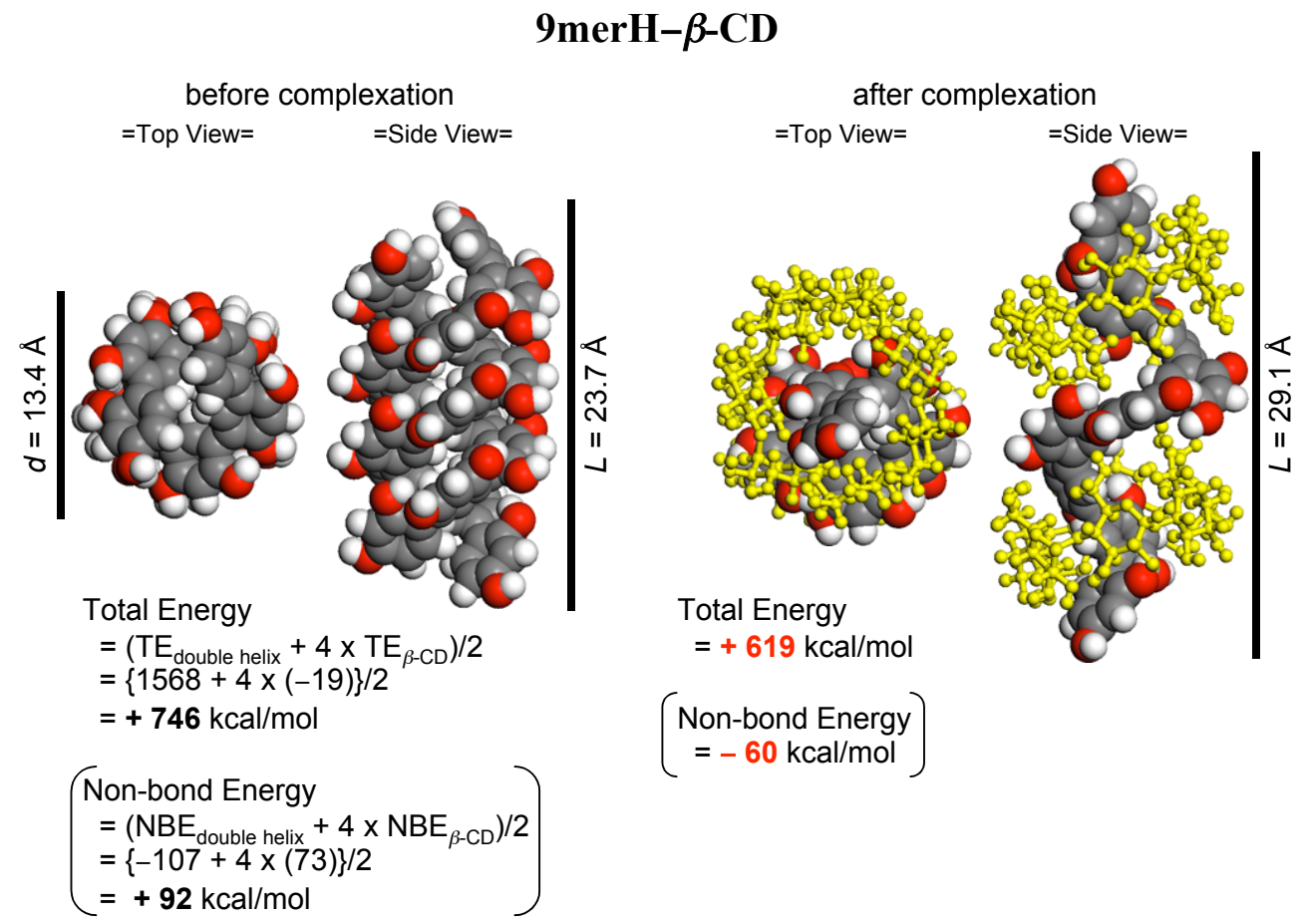

Figure S15. Molecular mechanics-calculated structures of the double helix of 9merH and the [3]pseudorotaxane 9 merH $\cdot(\beta-C D)_{2}$.

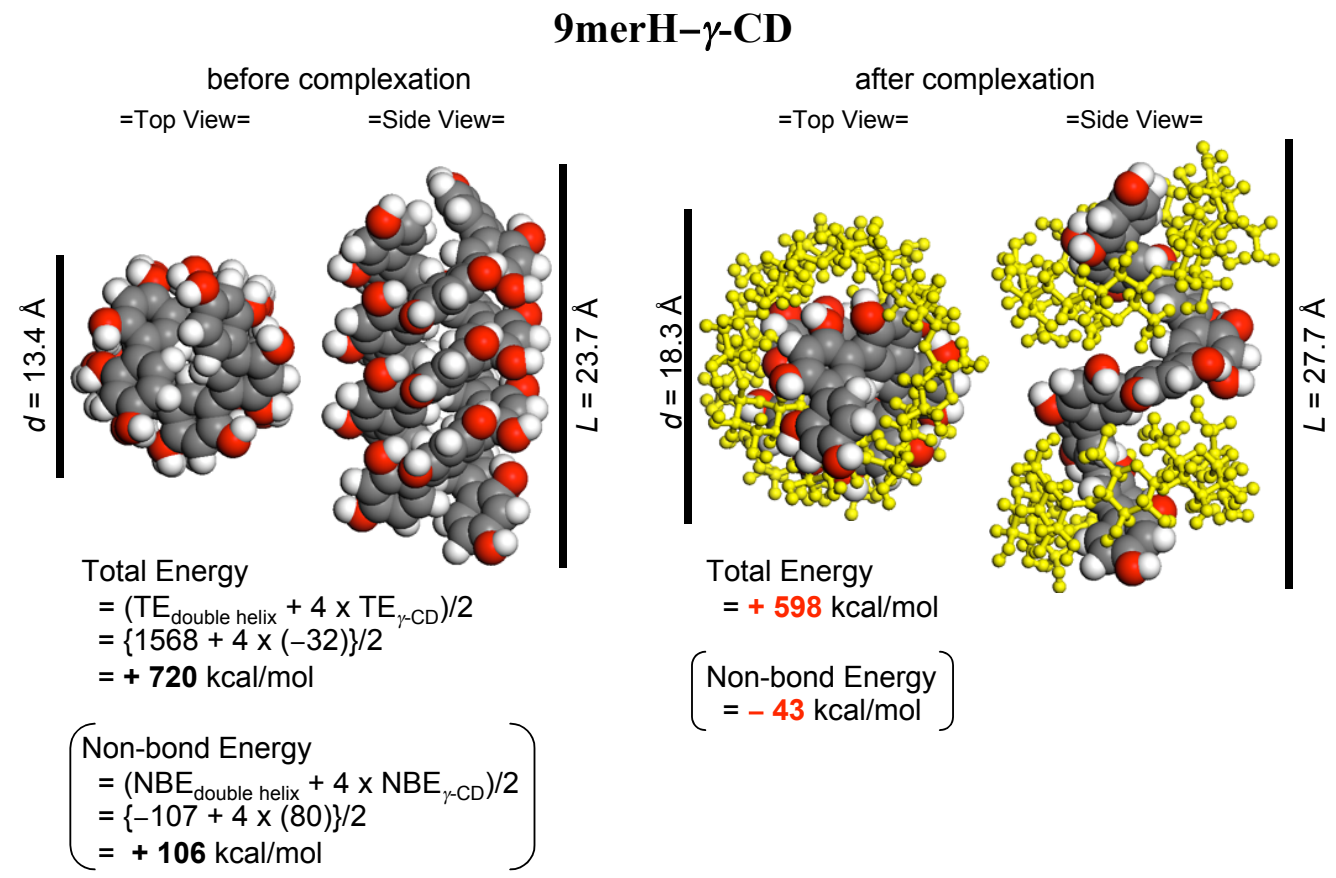

Figure S16. Molecular mechanics-calculated structures of the double helix of 9merH and the [3]pseudorotaxane $9 \mathbf{m e r H} \cdot(\gamma-\mathrm{CD})_{2}$. 


\section{Supramolecular Control of the Unwinding and Rewinding of the Double Helix of 9merH with CDs and an Adamantane Derivative}

The supramolecular switching of double and single helices of 9merH could be reversibly controlled in water. Upon complexation with $\beta$ - or $\gamma-\mathrm{CD}$, the double helix of 9merH changed to single-stranded helices entrapped within the hydrophobic cavity of CDs, whereas an addition of 1-aminoadamantane hydrochloride (Ad), which could be trapped more efficiently in the $\mathrm{CD}$ interior, resulted in the recovery of the original double helix. This cycle could be repeated at least two times. Weak hysteresis was observed when $\gamma$-CD and Ad were used (Fig. S16), probably because of a rather weak inclusion complexation of $\gamma$-CD with Ad in water as compared with that of $\beta$-CD. 

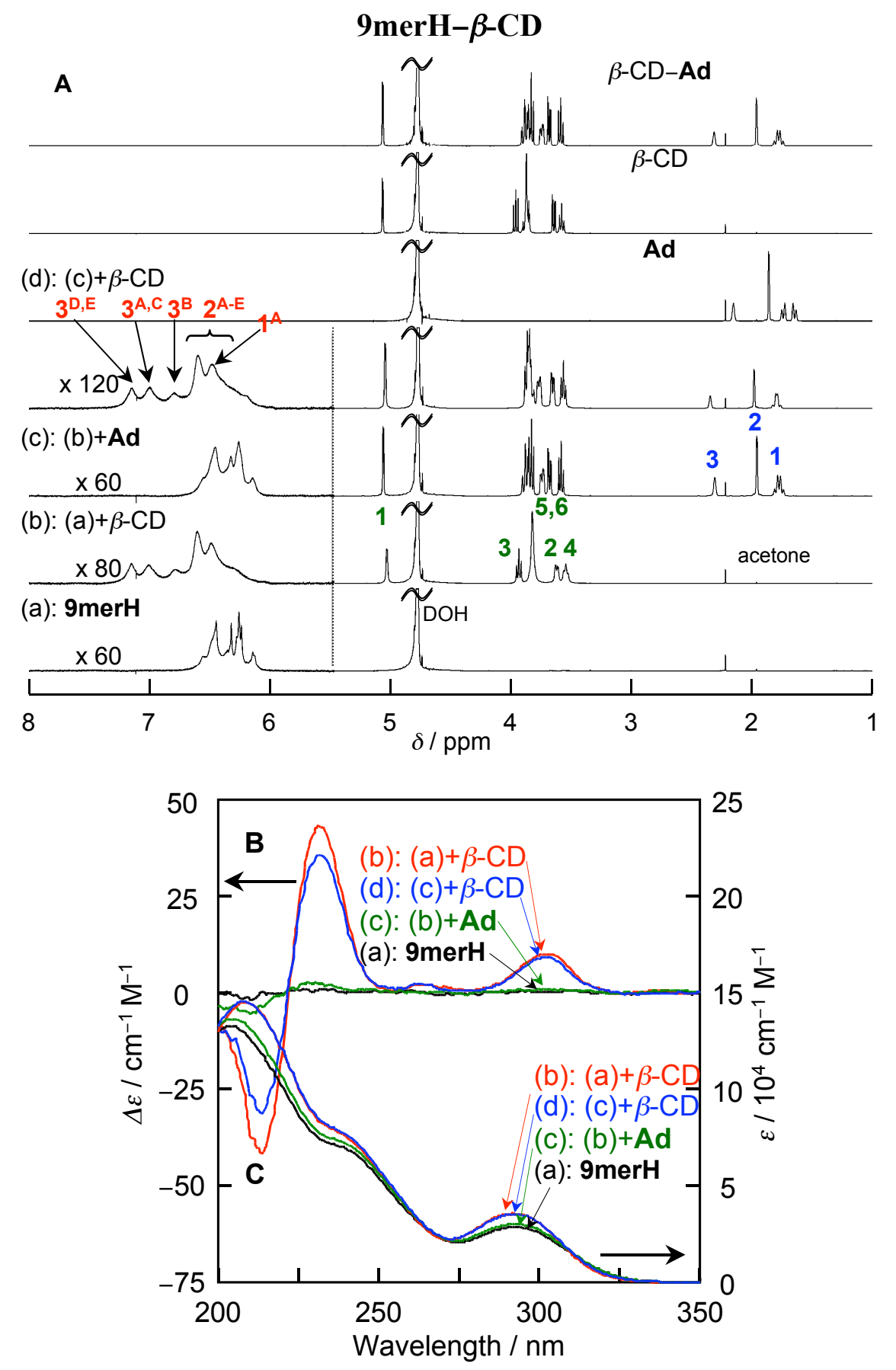

Figure S17. ${ }^{1} \mathrm{H}$ NMR (A), circular dichroism (B) and absorption spectra (C) of 9merH- $\beta$ CD-Ad mixtures (1/0/0 (a), 1/8/0 (b), 1/8/8 (c), 1/16/8 (d), mol/mol/mol) in $\mathrm{D}_{2} \mathrm{O}$ (pD = $5.8-6.0)$ at $25^{\circ} \mathrm{C}$. $[9 \mathrm{merH}]=0.625 \mathrm{mM}$. 

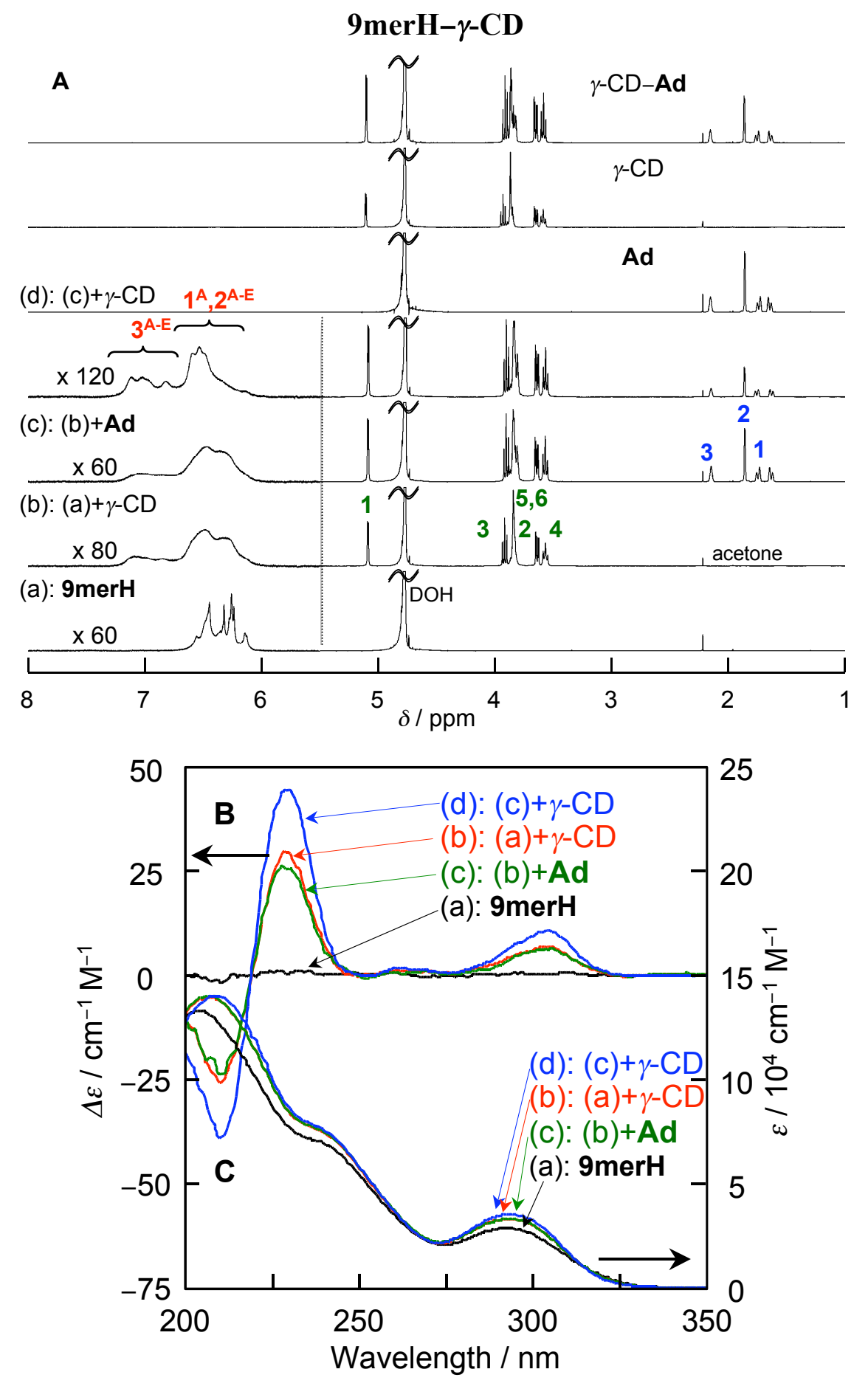

Figure S18. ${ }^{1} \mathrm{H}$ NMR (A), circular dichroism (B) and absorption spectra (C) of 9merH- $\gamma$ CD-Ad mixtures (1/0/0 (a), 1/8/0 (b), 1/8/8 (c), 1/16/8 (d), mol/mol/mol) in $\mathrm{D}_{2} \mathrm{O}$ (pD = $5.8-6.0)$ at $25{ }^{\circ} \mathrm{C} .[9 \mathrm{merH}]=0.625 \mathrm{mM}$. 


\section{References}

1 Goto, H.; Katagiri, H.; Furusho, Y.; Yashima, E. J. Am. Chem. Soc. 2006, 128, 7176-7178. 